\title{
Poesia, documento, autoria
}

Diana Klinger ${ }^{1}$

\section{O livro das postagens}

B: Tá foda. Tem um jornalista canadense todo arrebentado. E agora bateram no carinha da Mídia Ninja. Bateram muito. Quebraram o equipamento dele.

P: Caralho. Todos os que estamos fora da Praça temos que mobilizar as autoridades. É caso de urgência.

B.: Estou aqui online, P. , vamos dividir as ações. Já ligou para quem?

P: Eles batem e riem.

E.: A Praça Saens Peña está sitiada agora, com manifestantes gravemente feridos (braços quebrados, cortes profundos) e não chega ajuda médica. Ninguém entra e ninguém sai. Se alguém morar na Praça ou conhecer algum médico $\left(^{*}\right)$ que mora por aqui é importante ajudar! Policiais dispersaram com bombas um grupo com cerca de 300 manifestantes que tentou se aproximar do Maracanã.

A passagem acima pertence ao último livro de Carlito Azevedo, o Livro das postagens (2016). Com uma forte impronta narrativa, a publicação é dividida em duas partes: a primeira, "O livro do Cão", é um longo poema em que a primeira pessoa é a voz de um cachorro angustiado pela obrigação de ter de se expor, afirmando constantemente que "eu não deveria nem estar aqui [...] o autor deveria estar aqui" (Azevedo, 2016, p. 13). Na segunda parte, "O livro das postagens", "o autor" assume a primeira pessoa. Está recluso num quarto onde passa os dias traduzindo poesia, enquanto espera uma mulher voltar, e vê o mundo exterior através da janela do quarto e da internet. Essa voz em primeira pessoa que exibe o estilo reconhecível da poesia de Carlito Azevedo é cortada a toda hora por falas diversas, citações, postagens, mensagens inbox, assim como numa timeline de Facebook em que poemas convivem

\footnotetext{
${ }^{1}$ Doutora em literatura comparada e professora da Universidade Federal Fluminense (UFF), Niterói, RJ, Brasil. (Dorcid.org/0000-0002-9656-9933. E-mail: dianaklinger@gmail.com
} 
lado a lado com notícias, comentários e conversas, e em que todo tipo de referência aparece no mesmo plano, como na página do Livro das postagens a seguir (Figura 1).

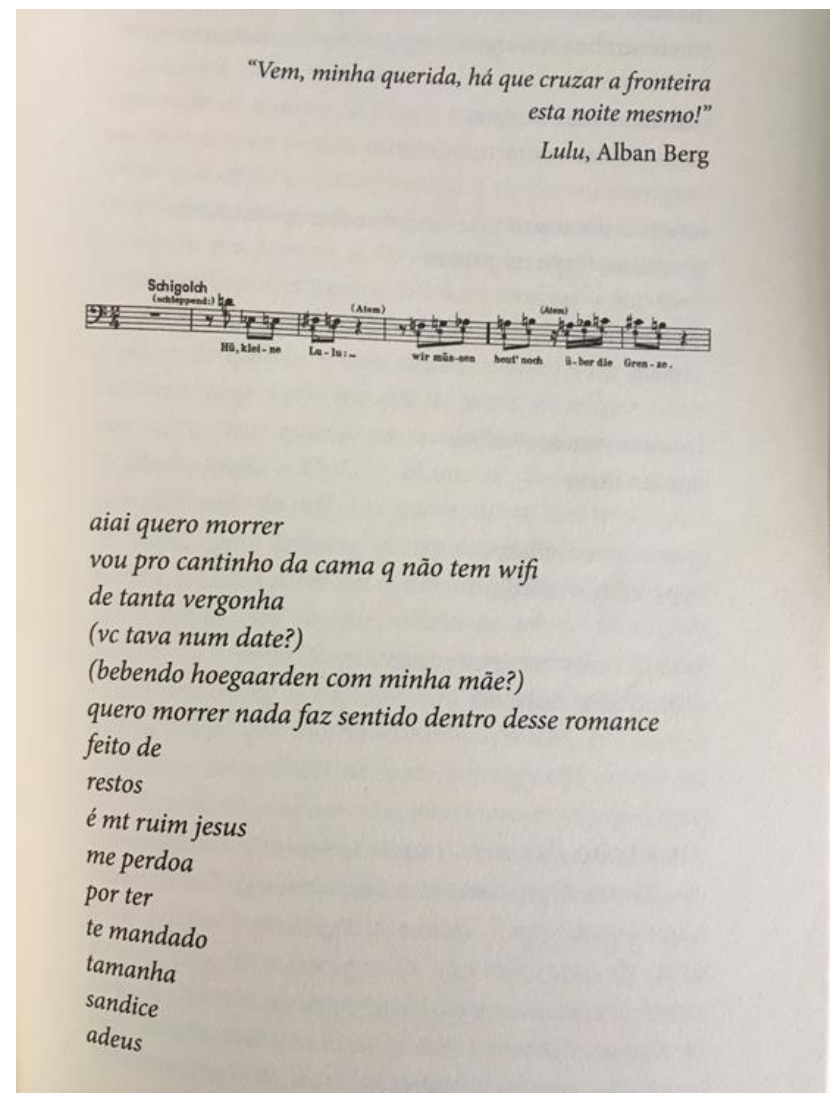

Figura 1 - Página 49 do Livro das postagens (Azevedo, 2016).

Embaixo da citação da ópera Lulu, de Alban Berg e da partitura, algo que parece uma mensagem inbox, alguém se desculpa pela falta de sentido, num romance feito de restos, como é feito de restos (de diferentes discursos) o próprio livro das postagens. Daí que seu título - Livro das postagens - ressoe o Livro das passagens, de Walter Benjamin, um projeto feito inteiramente de citações. Nesse tipo de passagens que são as timeline do século XXI, as mercadorias seriam 
as postagens ou "objetos linguísticos" e linguístico-visuais disponíveis para o consumidor. Essa classe de materiais ou "mercadorias" são "documentos" na medida em que um documento é "aquilo que pode circular, ser citado, que é verificável" (Reverseu, 2012, p. 1), mesmo que em si um documento não ateste nada, não seja um dado e não constitua uma voz imediata do acontecimento, como já apontara Foucault (1969, p. 13).

Vale a pena explorar diversos usos de documentos em projetos poéticos e livros de poesia publicados nos últimos anos, justamente na medida em que esses usos ao mesmo tempo implicam num deslocamento do sujeito poético, na apropriação de outras vozes e discursos, e produzem um estranhamento sobre a percepção desses documentos e do real para o qual eles apontam. No caso do Livro das postagens, considero que existe uma relação estreita entre este tipo de documento que são as postagens e o livro de poemas enquanto materialidade e tecnologia.

O livro aqui não é um mero suporte para a edição dos poemas, mas um princípio composicional de cuja materialidade também depende o sentido. Justamente uma das particularidades do Livro das postagens é que os poemas não têm nenhuma autonomia; apesar de ser um livro fragmentário, os poemas são avessos a qualquer possibilidade de antologização. Pois tudo aqui é uma questão de composição: esse é o procedimento mais importante em jogo. Por exemplo, na página 41 (Figura 2), que é a primeira da segunda parte (ou seja do "Livro das postagens").

Como apontava Roland Barthes (1984), toda fotografia diz "isto foi", remetendo ao instante do tempo capturado nela. A fotografia desta página do livro aponta simultaneamente a dois momentos separados por mais de 40 anos: o momento em que a fotografia foi tirada e o momento em que ela foi postada. 
com a legenda

Eu na Embaixada da Argentina

quando os exilados brasileiros

esperavam por notícias sobre

qual país iriam depois

do golpe no Chile

em 1973

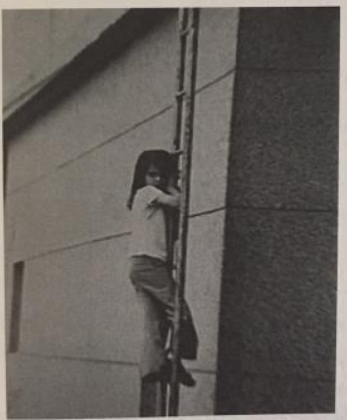

E então só consegui pensar em Z:

esta menina está parada como a flecha de Zenão.

Figura 2 - Página 41 do Livro das postagens (Azevedo, 2016).

A remissão, ainda, à flecha de Zenão faz dessa página uma muito significativa do livro - e reparemos que precisamos falar em páginas, não é possível abordar o livro ou os poemas em termos de estrofes ou versos, porque cada página do livro das postagens é um corte onde as postagens são um contínuo sem fim. Isso produz um contraste com esses materiais utilizados, esses restos de falas e citações do Facebook que acabam sumindo para sempre numa timeline: no livro, o universo potencialmente infinito e efêmero (das postagens digitais) se fecha, se cristaliza numa única versão, em papel, e a efemeridade desses materiais (sejam eles reais ou 
inventados, pouco importa para o caso) que somem em fração de segundo diante de nossos olhos numa "linha de tempo" eterniza-se num objeto, o livro, que - de acordo com o autor - foi sendo elaborado ao longo de vários anos. Inclusive porque essas postagens recuperadss e que se cristalizam no presente do livro criam outro tipo de constelação de tempos, porque são postagens que pertencem a momentos diferentes: por exemplo, convivem a manifestação na praça Saens Peña, que ocorreu na época da Copa do Mundo de 2014, com as ocupações das escolas pelos secundaristas, realizadas em 2016, entre outros acontecimentos.

Eu dizia que a composição é o procedimento fundamental, mas não se trata apenas da composição da página, mas, sim, a composição do livro como um todo. Em outras palavras, o livro passaria a ser a unidade mínima da poesia. E aqui resulta interessante pensar nos efeitos do contraste entre a materialidade do papel e a da tela, entre a tecnologia digital e a tecnologia do livro impresso. Em "Back to the future. O livro de poesia como crítica do livro em papel e do e-book", Osvaldo Silvestre (2016, p. 111) se pergunta pela materialidade do livro de poesia e pela forma como ela responde a uma ideia de livro em que "o devir digital foi retroativamente retificando numa lógica distribucional que reserva, para o livro em papel, as qualidades de materialidade, rigidez e unidirecionalidade e, ao livro digital, as qualidades de imaterialidade, flexibilidade e interatividade". "O livro de poesia em papel resiste melhor à Grande Migração para o digital do que o livro de ficção ou ensaio" (Silvestre, 2016, p. 110), e o crítico português se pergunta por que razão resiste o livro de poesia em papel, dada a impertinência do econômico no mundo da poesia que pareceria sugerir a conveniência de uma migração para um suporte digital.

Não é isso o que acontece, de fato: a autoria na poesia continua se afirmando pelo livro impresso, o livro impresso é o elemento legitimador de um "novo poeta", que pode até ter começado a publicar na web mas só se legitima no livro. E não existe crítica de poesia que não seja crítica de livros de poesia, sem contar com os vários pequenos empreendimentos de edição de poesia que existem no Brasil nos últimos anos, que prezam pelo cuidado com o livroobjeto. Apontar essa resistência do livro de poesia não significa 
atribuir conservadorismo ou espírito reativo ao mundo da poesia, antes parece indicar, diz Osvaldo Silvestre (2016, p. 113), que talvez "a contribuição do digital para recodificar a forma-livro não é tão radical como se pensa".

No caso do Livro das postagens, justamente, essa "resistência" está reforçada na própria composição, uma vez que uma possível edição digital mudaria completamente as conotações da edição no papel, e aqui justamente se põe em evidência que o suporte papel é também uma tecnologia e o livro em papel é um aparelho tecnológico capaz de produzir o congelamento do tempo, isto é, produzir o anacronismo, de uma forma que o digital não permitiria. Por isso, é interessante que essa segunda parte do Livro das postagens se abra com uma referência à flecha de Zenão. $\mathrm{O}$ paradoxo de Zenão (segundo o qual, Aquiles jamais conseguirá alcançar a tartaruga devido à infinita divisibilidade do movimento - e do tempo - que os tornaria impossíveis) ${ }^{2}$ produzido pelo choque de duas tecnologias. Algo semelhante - tornar a nova tecnologia anacrônica, a partir de um uso "desviante" da mesma fez Godard (2014) em seu Adeus à linguagem, um filme singular que mistura tecnologia 3D com 2D, sobrepondo-as por momentos, criando uma imagem cheia de "ruído", no limite do visível, que perturba a percepção do espectador.

$\mathrm{O}$ Livro das postagens faz alusão a Adeus à linguagem em pelo menos duas oportunidades. Uma, através do cachorro que assume a primeira pessoa em toda a primeira parte do livro, o "Livro do cão", pois no filme do diretor francês há uma presença constante de um cachorro e, em diferentes versos ao longo do poema, essa voz em primeira pessoa diz: "Marina Tsvetaeva me conhece", "Godard me conhece", "Maiakóvski me conhece", "Cézanne me conhece". A segunda alusão ao filme de Godard tem a ver com uma imagem do filme (que é também still e, portanto, uma cena destacada no longametragem) em que aparece o cachorro junto a um lago azul e um céu também de um azul impactante. Diz o poema de Carlito Azevedo (2016, p. 15):

\footnotetext{
${ }^{2}$ De acordo com o paradoxo enunciado pelo grego Zenão de Eleas, se a tartaruga começasse a corrida um metro antes de Aquiles, este jamais poderia alcançá-la, pois antes de percorrer um metro ele deveria percorrer metade de trajeto, e ante de percorrer metade, deveria percorrer a metade da metade e assim sucessivamente até o infinito.
} 


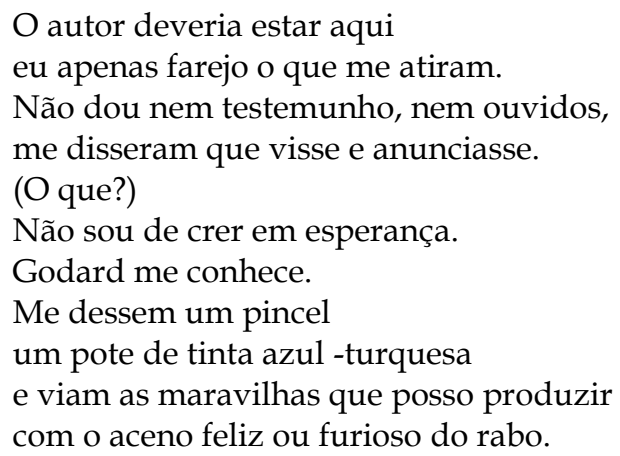

\section{Literatura não é documento}

"Literatura não é documento" é o título do ensaio de Ana Cristina Cesar (1980), cuja obra foi frequentemente lida em chave autobiográfica. Com efeito, pareceria que não há nada mais distante do que a poesia e o documento. No ensaio, Ana C. procurava intervir contra uma ideia de literatura lida como monumento ou patrimônio, e assim se afastar também "da premissa do engajamento". Paralelamente, em seus poemas ela usava elementos do diário íntimo, da anotação de caderneta, a carta, a confissão e o bilhete. É sobre esse paradoxo que se constrói sua obra. "Namorar o documento, o local, o testemunho; brincar com eles; reinvesti-los; ir lá; desejar uma impossível reconstituição", disse Ana C. em entrevista (Lima, s.d.).

"Namorar o documento" parece ser o que fazem alguns livros de poemas publicados no Brasil nos últimos anos: além do Livro das postagens, também era um dos procedimentos do livro anterior de Carlito Azevedo (2009), Monodrama, em que aparece, por exemplo, um fragmento de uma matéria de jornal no poema "Margens". Procedimentos semelhantes aparecem em Câmera Lenta, de Marília Garcia (2017), que utiliza, por exemplo, matérias de jornais e sites de notícias sobre a queda do avião da Malaysia Airlines em 2014; em Ano novo, de Leila Danziger (2016), um livro de poemas feito a partir de um arquivo familiar de fotografias, cartas e agendas; em Elefantes dentro de um sussurro, de Marcelo Reis de Melo (2017), em que há documentos sobre a Mata 
Atlântica; ou em Mais cotidiano do que o cotidiano (2013), de Alberto Pucheu, um livro composto de fragmentos heterogêneos e que inclui, por exemplo, uma arguição de uma banca de doutorado. Coincidentemente, alguns anos atrás, num texto sobre o trabalho do artista chileno Alfredo Jaar, Didi-Huberman (2008) apontava um "devir documento da arte contemporânea".

Olhando a cena da poesia no Brasil hoje, é possível argumentar também algo em torno desse devir, a partir de uma rara conjunção entre poesia e documento. Porém, seria importante distinguir "documento", que designa a natureza de um objeto, seu estatuto, de "documental", que diz respeito a um projeto e uma intencionalidade. Enquanto a estética documental frequentemente se aproxima da forma do documento, os dois podem também se afastar, uma vez que um testemunho não tem necessariamente uma forma documental e uma imagem documental pode ser inventada (Reverseu, 2012, p. 1). Nesses poemas a que faço referência aqui é justamente isso que acontece: há um uso do documento que se insere numa estética não documental, numa montagem heterogênea de materiais, que em boa medida resulta num procedimento em que a poesia seria como uma lente que deforma o real. Uma das questões que exploro neste artigo é de que forma o uso desses materiais produz uma certa proposta de percepção do real e, ao mesmo tempo, incide no conceito de autoria.

Em outubro de 2015, o poeta e performer americano Kenneth Goldsmith leu, durante meia hora, diante de uma plateia de 100 pessoas na Brown University, seu poema "The body of Michael Brown". Michael Brown foi um rapaz negro que, em 2014, aos 18 anos, foi morto a tiros por um policial branco em Ferguson. $\mathrm{O}$ "poema" de Goldsmith na verdade reproduzia na íntegra o laudo da autópsia de Brown, o que levantou uma enorme polêmica, em que o performer foi acusado de espectacularizar essa morte. ${ }^{3}$ É claro que podemos lembrar aqui de vários outros poemas sobre notícias, como o "Poema tirado de uma notícia de jornal", de Manuel Bandeira, mas enquanto neste poema a notícia era o ponto de partida para uma elaboração subjetiva/criativa do poeta, no texto de Goldsmith não havia de fato nenhuma criatividade, só a

\footnotetext{
${ }^{3}$ Ver, por exemplo, a matéria no The New Yorker (Wilkinson, 2015).
} 
repetição literal do documento: na verdade, a dimensão criativa ficava exclusivamente por conta da performance oral. Certa vez Goldsmith disse que os juízos em torno da autoria (ele disse: "do plágio e do copyright") do século XXI são como os juízos em torno da obscenidade do século XIX.4 No entanto, nessa performance, "The body of Michael Brown", mesmo não havendo um processo judicial, houve escândalo (inclusive, por causa disso, Goldsmith pediu para a universidade não disponibilizar o vídeo da performance na web): a questão da autoria e da obscenidade parecem coincidir.

"Context is the new content" - o contexto é o novo conteúdo -, dizia Goldsmith (2011) em "Uncreative writing" ("Escrita não criativa"). À primeira vista poderíamos dizer que a frase "o contexto é o conteúdo" nada mais é do que uma versão em máxima ou slogan da concepção de arte de Duchamp, mas, na verdade, essa frase traz outras camadas de sentido, pois "o contexto é o conteúdo" parece uma tradução contemporânea de "o meio é a mensagem", a famosa frase de Marshall McLuhan, segundo a qual o meio seria entendido como uma extensão do corpo humano, por sua capacidade de modificar o curso e o funcionamento das atividades e das relações humanas. Por outro lado, "o contexto é o conteúdo" também parece remeter à recomendação de Wittgenstein: "não olhe para o sentido, olhe para o uso".

Mas, voltando à Uncreative writing, a referência central do texto de Goldsmith é justamente o Livro das passagens, de Benjamin, o qual ele diz ser "o melhor livro de escrita não-criativa", "o mais importante trabalho de apropriação". Segundo Goldsmith, a forma como lemos O livro das passagens, que não era um livro, mas uma série de fichas, é muito próxima de como aprendemos a usar a web: pulando hipertextualmente de um lugar a outro, navegando segundo um roteiro próprio e imprevisível, através da imensidade dela, convertidos em flaneurs virtuais (2011, s.p.). Mas o paralelo não termina aí, porque na verdade cada página web é em si mesma uma constelação que se compõe num instante e que desaparece rapidamente. Se recarregamos (fazemos "reload") a página principal de um jornal, por exemplo, não será exatamente igual à que era uns

\footnotetext{
4 “Today's plagiarism and copyright battles are to the twenty-first century what the obscenity trials were to the twentieth" (Goldsmith, 2015).
} 
segundos atrás. No caso de uma timeline, com certeza será completamente diferente. Goldsmith sustenta que a página web, com sua forma constelar, equivale ao conceito de "imagem dialética", na medida em que, nesse espaço, passado e presente se fusionam por um momento criando uma imagem fugaz.

A partir dessa noção de escrita não criativa, Goldsmith compõe poemas que são inteiramente apropriações de outros discursos, como é o caso de Day ou de Traffic. Em Day, um livro publicado em 2003, Goldsmith se propõe a copiar integralmente o jornal de um dia, palavra a palavra, letra a letra, incluindo as propagandas, horários de cinema etc. $\mathrm{O}$ "exercício" partia da proposta de ser o menos criativo possível e, no entanto, ao longo do processo, Goldsmith se viu diante de dezenas de decisões editoriais a tomar, desde questões de tipografia, diagramação, até como proceder a cópia, se seguindo a continuidade espacial ou o roteiro proposto pelo jornal quando diz, por exemplo, que uma notícia continua na página $x$. Traffic foi publicado nos Estados Unidos em 2006, e nele Goldsmith basicamente transcreve as informações do trânsito transmitidas pelo rádio ao longo de um dia. ${ }^{5}$ Aqui no Brasil, a editora Luna Parque ${ }^{6}$ lançou um pequeno livrinho, em "versão compacta e dublada", intitulado Trânsito (2016), em que se tratava de uma transmissão de rádio da cidade de São Paulo, cidade sede daquela editora. Esta possibilidade de "dublagem" em que o livro em português é inteiramente diferente do texto em inglês, mas o autor continua aparecendo como sendo Kenneth Goldsmith, implica então que autoria não diz respeito às palavras usadas, mas é uma questão de ideias, intervenções e decisões editoriais. Assim, a famosa resposta que Mallarmé dá a seu amigo Degas - "a poesia não é feita de ideias e sim de palavras" perderia sua vigência nesse contexto.

\footnotetext{
${ }^{5}$ Em 2011, convidado para uma celebração da poesia norte-americana na Casa Branca, Goldsmith leu partes desse livro. Esta informação pode não ser muito relevante para se pensar o projeto de Goldsmith, mas é interessante para percebermos o lugar dele dentro do contexto cultural norte-americano.

${ }^{6}$ Luna Parque é justamente um desses empreendimentos editoriais contemporâneos de edição de poesia mencionados no início deste texto, que funciona como uma pequena editora com um catálogo muito seleto e um cuidado particular com a materialidade dos livros.
} 


\section{Poesia e antimonumento}

No livro Sessão, também editado pela Luna Parque, em 2017, Roy David Frenkel selecionou discursos que fizeram os deputados federais em 2016, durante o anúncio a favor ou contra o impeachment da então presidente da República, Dilma Rousseff. Os trechos foram transcritos no livro e submetidos a uma diagramação em forma de poemas. Mas não se trata de uma mera transcrição: no texto impresso, através dos cortes e espaçamentos, aspectos dos discursos se destacam, provocando uma leitura irônica em relação com as intenções dos autores desses discursos, por exemplo neste fragmento:

\author{
Um dia \\ senhores, \\ há pouco mais \\ de 500 anos, \\ homens inspirados \\ também pela honra \\ atravessaram o mar \\ tenebroso para fundar \\ aqui \\ aquela que, \\ entre outras mil, \\ és tu,
}

ó

\section{Brasil}

Pátria

Amada. (Frenkel, 2017, p. 22)

Aqui, os deslocamentos gráficos de "Brasil" e "Pátria" (destacando a citação do hino nacional) permitem outra leitura, que remete a um imaginário de um lirismo fácil (és tu... ó amada). Assim também as motivações pessoais, familiares, dos deputados evocadas em seus discursos adquirem tons humorísticos por se tornarem, no contexto de um livro "de poemas", uma somatória de clichês (Coelho, 2017, p. 242).

\section{Hoje,}

quando saí de casa,

passei no quarto dos meus 


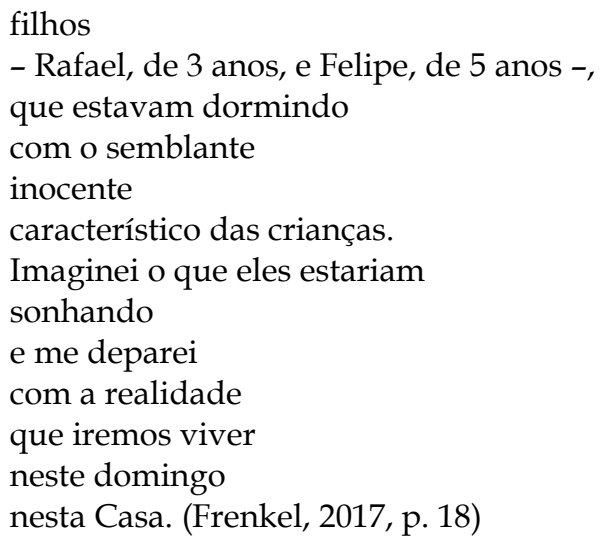

Não houve manipulação do conteúdo dos discursos dos deputados, somente da forma. Na passagem da fala para a escrita, houve uma transcrição (isto é, uma mudança de contexto), uma mudança nas pausas - através dos versos - e uma retirada do nome do autor de cada de um deles. E aqui poderíamos dizer, como o cão do Livro das postagens, de Carlito Azevedo: "o autor é que deveria estar aqui!" Os vários “eus" que aparecem nos poemas, não só não têm como referente um único eu (como se esperaria, digamos, em qualquer livro de poemas), mas também não têm nenhuma relação com o eu que assina a autoria do livro.

Nessa "repetição" ipsis litteris das falas dos deputados nos poemas instala-se uma diferença crucial não apenas pelo fato mais óbvio de que o ato de fala fica desativado, mas também na medida em que a performance oral tem sido substituída pela dimensão visual, a espacialização do poema determina uma leitura de pausas e silêncios diferentes das palavras que foram pronunciadas no contexto original. Repetidos nesse novo contexto, elas resistem à banalidade com que foram ditas e recebidas nesse fatídico episódio para a história do Brasil que foi o 17 de abril de 2016, "naquela noite estranhamente atravessada por fogos de artifício" (Coelho, 2017, p. 244). O contexto é o conteúdo, disse Goldsmith. Assim, se naquele "fatídico domingo" o Brasil ficou conhecendo o nome e o rosto de cada um dos deputados, e se deparou com a voz, o gesto e a atitude exaltada da maioria deles, no livro Sessão, esses discursos passam a circular no anonimato, como uma espécie de antiready made (e nesse 
sentido, me afasto das resenhas que se fizeram do livro aproximando o procedimento ao readymade). Se Duchamp, com o urinol, retirava um objeto produzido em série e singularizava-o dotando-o de assinatura, o gesto de Roy Frenkel consiste, ao contrário, em retirar a singularidade e a assinatura dos discursos, e torná-los objeto de uma voz única, anônima e amorfa, algo assim como um "inconsciente coletivo" que essas subjetividades pareciam encarnar. Por sua vez, este modo de apropriação do discurso do outro, a partir dessa distância, desvirtuaria também a particularidade do ready made, que consiste em estabelecer uma equivalência entre "escolher e fabricar, consumir e produzir" (Bourriaud, 2009, p. 22). Isso porque este "modo de usar" o discurso dos deputados (não arriscaria a chamar de "discurso político"), convoca um determinado leitor, uma determinada comunidade de recepção.

Sem o compartilhamento de certos pressupostos e certos valores, não apenas sobre arte e literatura, mas sobretudo sobre os acontecimentos políticos, os "poemas" seriam completamente ilegíveis. O resultado é algo assim como a construção de um lugar de memória que funcionaria como antimonumento. Se o monumento congrega, "é uma das formas como a sociedade se mitologiza a si própria" (Tatián, 2012), o efeito de Sessão é uma dissolução da mitologia que sustenta o monumento nacional, ao investir nessa divisão, nessa "sessão" ou "cesura" que se percebe na sociedade brasileira com maior insistência a partir da votação, na Câmara, da destituição da presidente da República. Literatura não é documento, mas pode servir para construir antimonumentos.

\section{Poesia e desencontro com o real}

Pelo dito ate aqui é evidente que o que interessa pensar da relação entre a poesia e os documentos não tem a ver com uma operação de registro, na linha de um realismo ou um neodocumentalismo. Também não se trata de "poesia de circunstância", porque esta aponta para uma situação referencial a partir de uma elaboração poética de um sujeito, enquanto os poemas aqui comentados se apropriam de "objetos linguísticos" ("documentos") e utilizam-nos a partir de procedimentos de corte e montagem numa nova composição. Em outras palavras, não se trata de uma representação do real, mas de uma repetição de discursos. 
Dessa forma, esses poemas, essas performances ou esses livros de poemas que se recusam a assumir a primeira pessoa, ou a fazê-la coincidir com a ideia de autoria, colocam em suspense não apenas a noção de criação mas também de subjetividade a ela associada. No entanto, não é um objetivismo que emerge daí, nem é exatamente o tipo de problematização da autoria que surge do gesto de Duchamp, digamos. Porque se nele havia um procedimento de singularização (outorgar assinatura a um produto produzido em série), aqui o que acontece é quase o inverso, pois o que surge é uma noção de anonimato ou, melhor, de impessoalidade, noção esta que vem assomando como operador crítico em alguns discursos sobre arte e literatura, ${ }^{7}$ a partir de algumas discussões filosóficas contemporâneas. Por exemplo, em Terza Pessoa. Politica della vita e filosofia dell'impersonale, Roberto Esposito (2007) argumenta, retomando uma genealogia que inclui Simone Weil, Levinas, Blanchot, Foucault e Deleuze, em favor de uma terceira pessoa como uma "não pessoa", um "neutro", da escrita como um espaço de despersonalização.

Por sua vez, o que se configura nesses livros de poemas comentados aqui é um uso dos documentos que põe em cena uma noção do real. Como diz Raul Antelo, "a poesia persegue o real", definido como "o ponto do impossível de toda formalização", como diria Lacan, "um point de pensée, que revela a impossibilidade de qualquer pensamento, de toda racionalização" (Antelo, 2016, p. 91). Acredito que o uso dos documentos nessa poesia contemporânea de que me ocupo aqui tem a ver com esse desencontro com o real, ou seja: os documentos estão aí não para atestar um certo real e sim para produzir um desajuste na percepção do real. Na mudança de contexto de uma fala, na perda da relação com o sujeito de sua enunciação, na mistura com outras vozes ou instâncias de produção do mesmo discurso, a percepção do fragmento do real para o que o documento aponta vai sendo redimensionada. Então é nesse sentido que aponto para essa relação da poesia com os documentos como fragmentos do real, para pensar não "a literatura como documento", como dizia Ana Cristina Cesar, nem um suposto "retorno ao real", mas, ao contrário, para mostrar a maneira como a poesia usa o documento como forma de aproximação de um real na

${ }^{7}$ Por exemplo, os textos de Florencia Garramuño: "O outro avança sobre mim" (2016) e "Depois do sujeito: formas narrativas contemporâneas e vida impessoal" (2017). 
forma de uma repetição que mostra, em sua diferença, um desajuste em que o poema, e especialmente o livro de poemas como mídia sobrevivente, leva a um estranhamento da percepção desse real.

\section{Referências}

ADEUS à linguagem (2014). Direção: Jean-Luc Godard. Paris: Imivision.

ANTELO, Raul (2016). A poesia nao pensa, ainda. In: SCRAMIN, Susana (Org.). Alteridades na poesia: riscos, aberturas, sobrevivências. São Paulo: Iluminuras.

AZEVEDO, Carlito (2016). Livro das postagens. Rio de Janeiro: 7 Letras.

BARTHES, Roland (1984). A câmara clara: nota sobre a fotografia. Rio de Janeiro: Nova Fronteira.

BOURRIAUD, Nicolas (2009). Postproducción: la cultura como escenario Modos en que el arte reprograma el mundo contemporáneo. Buenos Aires: Adriana Hidalgo.

CESAR, Ana Cristina (1980). Literatura não é documento. Brasília: Funarte.

COELHO, Eduardo (2017). Ressaca do ano seguinte. Posfácio. In: FRANKEL, Roy David. Sessão. São Paulo: Luna Parque. p. 237-244.

DIDI-HUBERMAN Georges (2008). La emoción no dice yo. Diez fragmentos sobre la libertad estética. In: DIDI-HUBERMAN Georges et al. Alfredo Jaar: la política de las imágenes. Santiago de Chile: Metales Pesados.

ESPOSITO, Roberto (2007). Terza persona. Politica della vita e filosofia dell'impersonale. Torino: Einaudi.

FOUCAULT, Michel (1969). L'Archéologie du savoir. Gallimard : Paris.

FRANKEL, Roy David (2017). Sessão. São Paulo: Luna Parque.

GARRAMUÑO, Florencia (2016). O outro avança sobre mim. Estudos de Literatura Brasileira Contemporânea, Brasília, n. 48, p. 11-28, maio/ago. 2016.

GARRAMUÑO, Florencia (2017). Depois do sujeito: formas narrativas contemporâneas e vida impessoal. Estudos de Literatura Brasileira Contemporânea, Brasília, n. 50, p. 102-111, jan./abr. 2016.

GOLDSMITH, Kenneth (2011). Uncreative writing. Managing language in the digital age. New York: Columbia University Press. 
GOLDSMITH, Kenneth (2015). I look to theory only when i realize that somebody has dedicated their entire life to a question i have only fleetingly considered. Poetry, Chicago, $1^{\circ}$ abr. Disponível em: <https://goo.gl/CK1n3s>. Acesso em: 10 out. 2017.

LIMA, Manoel Ricardo de [S.d]. Ler Ana C. é namorar um documento. Suplemento Pernambuco, Recife. On-line. Disponível em: <https://goo.gl/G9QP7H>. Acesso em: 10 out. 2017.

REVERSEAU, Anne (2012). Ce que la poésie fait du document: note méthodologique sur les insertions, les emprunts et les listes dans les années 1920. Fabula, Les colloques, Ce que le document fait à la littérature (1860-1940), Paris, 15 set. Disponível em: <https://goo.gl/92CxzH>. Acesso em: 14 jun. 2017.

SILVESTRE, Osvaldo (2016). Back to the future. O livro de poesia como crítica do livro em papel e do e-book. In: PEDROSA, Celia; ALVES, Ida (Org.). Poesia contemporânea. Voz, imagem, materialidades. Belo Horizonte: Editora da UFMG.

TATIÁN, Diego (2012). Lo impropio. Buenos Aires: Excursiones.

WILKINSON, Alec (2015). Something Borrowed. The New Yorker, New York, 5 out. On-line. Disponível em: <https://goo.gl/Cgwpxt>. Acesso em: 10 out. 2017.

Recebido em 31 de março de 2018.

Aprovado em 26 de junho de 2018.

\section{Nota 1}

A autora é pesquisadora da Fundação de Amparo à Pesquisa do Estado do Rio de Janeiro - Faperj (Jovem Cientista de Nosso Estado) e do Conselho Nacional de Desenvolvimento Científico e Tecnológico - CNPq.

\section{Nota 2}

Uma primeira versão deste texto foi apresentado no I Colóquio Sentidos e Tecnologias: Rituais da Percepção, organizado pela Red Latinoamericana de Investigaciones em Prácticas y Medios de la Imagen, realizado na Universidade Federal Fluminense, em julho de 2017. Agradeço aos organizadores pelo convite para participar do evento e pelo frutífero diálogo que contribuiu no desenvolvimento deste trabalho. 


\section{resumo/abstract/resumen}

\section{Poesia, documento, autoria}

Diana Klinger

O texto busca comprender procedimentos presentes em alguns livros de poesia contemporânea que, por meio do uso de documentos, ao mesmo tempo questionam a instância de autoria e produzem um estranhamento na percepção do real. Nos casos abordados, o livro de poemas se apresenta como unidade mínima da poesia, o que nos leva a pensar questões que envolvem o suporte - a mídia impressa - como fundamentais para a recepção destas obras.

Palavras-chave: autoria, documento, poesia contemporânea, realidade.

\section{Poetry, document, authorship}

\section{Diana Klinger}

This essay seeks to understand procedures found in various contemporary poetry books that, through the use of documents, simultaneously question the role of authorship and produce a sense of estrangement in the perception of the real. In the examples examined here, the book of poems is presented as a minimal unit of poetry. This understanding launches a series questions concerning the underpinning of the genre - the printed media - as a fundamental element in the reception of these works.

Keywords: authorship, document, contemporary poetry, reality.

\section{Poesía, documento, autoría}

\section{Diana Klinger}

Este texto busca comprender los procedimientos presentes en algunos libros de poesía contemporánea que, a través del uso de documentos, cuestionan la instancia de autoría y al mismo tiempo producen un extrañamiento en la percepción de la realidad. En los casos abordados, el libro de poemas se presenta como unidad mínima de la poesía, lo que nos lleva a pensar cuestiones que implican al soporte - el medio impreso- como fundamental para la recepción de estas obras.

Palabras clave: autoría, documento, poesía contemporánea, realidad. 